\title{
New Advances in the Management of Cytomegalovirus in Allogeneic Haemopoietic Stem Cell Transplantation
}

\author{
Michelle K.Yong ${ }^{1-3}$, David Gottlieb ${ }^{4-6}$, Julian Lindsay ${ }^{3,7}$, Jen Kok $^{8}$, William Rawlinson ${ }^{9}$, Monica \\ Slavin ${ }^{1-3}$, David Ritchie ${ }^{10,11}$, Ashish Bajel ${ }^{10}$, Andrew Grigg ${ }^{3,12}$ \\ ${ }^{1}$ Department of Infectious Diseases, Peter MacCallum Cancer Centre, Melbourne, VIC \\ Australia \\ ${ }^{2}$ The Peter Doherty Institute for Infection and Immunity, The University of Melbourne and \\ Royal Melbourne Hospital, Melbourne, VIC Australia \\ ${ }^{3}$ National Centre for Infections in Cancer, Peter MacCallum Cancer Centre, Melbourne, VIC \\ Australia \\ ${ }^{4}$ Department of Haematology and Bone Marrow Transplantation, Westmead Hospital, \\ Sydney, NSW Australia \\ ${ }^{5}$ Westmead Institute for Medical Research, University of Sydney, Sydney, NSW Australia \\ ${ }^{6}$ Sydney Cellular Therapies Laboratory, Westmead Hospital, Sydney NSW Australia \\ ${ }^{7}$ Pharmacy Department, Royal North Shore Hospital, NSW, Australia \\ ${ }^{8}$ Centre for Infectious Diseases and Microbiology Laboratory Services, Institute of Clinical \\ Pathology and Medical Research, NSW Health Pathology, Westmead Hospital, NSW, \\ Australia \\ ${ }^{9}$ NSW Health Pathology, Prince of Wales Hospital, NSW, Australia \\ ${ }^{10}$ Clinical Haematology, Peter MacCallum Cancer Centre and Royal Melbourne Hospital, \\ Melbourne, Australia \\ ${ }^{11}$ Department of Medicine, University of Melbourne, Melbourne, VIC, Australia \\ ${ }^{12}$ Department of Clinical Haematology and Olivia Newton John Cancer Research Institute, \\ Austin Hospital, Melbourne, VIC, Australia
}

\section{Corresponding author:}

Michelle Yong

Department of Infectious Diseases

Peter MacCallum Cancer Centre

305 Grattan Street

Melbourne, VIC 3000

Australia

Tel: + 61385597991

Fax: + 61385597379

Email: Michelle.Yong@unimelb.edu.au

\section{Word Count}

Abstract: 108

Main body: 2975 words

Tables: 3

This is the a author manuscript accepted for publication and has undergone full peer review but has not been through the copyediting, typesetting, pagination and proofreading process, which mayKeyndondsifferences between this version and the Version of Record. Please cite this article as doi: 10.1111/imj.14462

This article is protected by copyright. All rights reserved. 
Cytomegalovirus, haemopoietic stem cell transplantation, CMV-specific T cell therapy, CMV immune monitoring, letermovir, maribavir

\begin{abstract}
Cytomegalovirus (CMV) viremia continues to be a frequent complication in the post haemopoietic stem cell transplant (HSCT) period despite a low incidence of CMV end-organ disease. A number of significant advances in the understanding and management of CMV infection have occurred in the last few years including improved diagnostics, monitoring of CMV immunity, availability of novel anti-CMV drugs, and emerging use of immunotherapies including CMV-specific $T$ cell infusions. In addition to reviewing these advances we also explore some of the more practical prescribing issues of the older and newer CMV drugs including cost, toxicity and drug interactions to help clinicians navigate this new era of CMV management.
\end{abstract}




\section{New Advances in the Management of Cytomegalovirus in Allogeneic Haemopoietic Stem Cell Transplantation}

Michelle K.Yong ${ }^{1-3}$, David Gottlieb ${ }^{4-6}$, Julian Lindsay ${ }^{3,7}$, Jen Kok ${ }^{8}$, William Rawlinson ${ }^{9}$, Monica Slavin $^{1-3}$, David Ritchie ${ }^{10,11}$, Ashish Bajel ${ }^{10}$, Andrew Grigg ${ }^{3,12}$

${ }^{1}$ Department of Infectious Diseases, Peter MacCallum Cancer Centre, Melbourne, VIC Australia

${ }^{2}$ The Peter Doherty Institute for Infection and Immunity, The University of Melbourne and Royal Melbourne Hospital, Melbourne, VIC Australia

${ }^{3}$ National Centre for Infections in Cancer, Peter MacCallum Cancer Centre, Melbourne, VIC Australia

4 Department of Haematology and Bone Marrow Transplantation, Westmead Hospital, Sydney, NSW Australia

${ }^{5}$ Westmead Institute for Medical Research, University of Sydney, Sydney, NSW Australia

${ }^{6}$ Sydney Cellular Therapies Laboratory, Westmead Hospital, Sydney NSW Australia

${ }^{7}$ Pharmacy Department, Royal North Shore Hospital, NSW, Australia

${ }^{8}$ Centre for Infectious Diseases and Microbiology Laboratory Services, Institute of Clinical Pathology and Medical Research, NSW Health Pathology, Westmead Hospital, NSW, Australia

${ }^{9}$ NSW Health Pathology, Prince of Wales Hospital, NSW, Australia

${ }^{10}$ Clinical Haematology, Peter MacCallum Cancer Centre and Royal Melbourne Hospital, Melbourne, Australia

${ }^{11}$ Department of Medicine, University of Melbourne, Melbourne, VIC, Australia

${ }^{12}$ Department of Clinical Haematology and Olivia Newton John Cancer Research Institute, Austin Hospital, Melbourne, VIC, Australia

Corresponding author:

Michelle Yong

Department of Infectious Diseases

Peter MacCallum Cancer Centre

305 Grattan Street

Melbourne, VIC 3000

Australia

Tel: + 61385597991

Fax: + 61385597379

Email: Michelle.Yong@unimelb.edu.au

Word Count

Abstract: 108

Main body: 2975 words 
Tables: 3

References: 35

\title{
Keywords:
}

Cytomegalovirus, haemopoietic stem cell transplantation, CMV-specific T cell therapy, CMV immune monitoring, letermovir, maribavir

\begin{abstract}
Cytomegalovirus (CMV) viremia continues to be a frequent complication in the post haemopoietic stem cell transplant (HSCT) period despite a low incidence of CMV end-organ disease. A number of significant advances in the understanding and management of CMV infection have occurred in the last few years including improved diagnostics, monitoring of CMV immunity, availability of novel anti-CMV drugs, and emerging use of immunotherapies including CMV-specific T cell infusions. In addition to reviewing these advances we also explore some of the more practical prescribing issues of the older and newer CMV drugs including cost, toxicity and drug interactions to help clinicians navigate this new era of CMV management.
\end{abstract}

\section{Introduction}

Cytomegalovirus (CMV) infection is the most frequent infectious complication following allogeneic haemopoietic stem cell transplantation (HSCT) and is associated with adverse transplant outcomes and additional healthcare costs(1). Significant advances in the management of CMV have occurred in recent years, including improvements in viral load monitoring (with the use of international standards for assay comparison), immune monitoring diagnostics such as interferon gamma release assays, new antiviral treatments with novel mechanisms of action such as terminase inhibitors (letermovir) and direct kinase inhibitors (maribavir), and the emerging use of CMV-specific T cell therapies. In this review we evaluate these changes and provide an updated overview for clinicians managing CMV infection in allogeneic HSCT. 


\section{Epidemiology}

The CMV allograft landscape is changing. Currently two-thirds of all seropositive HSCT recipients will develop CMV viremia in the post-transplant period with the most important risk factor being pre-transplant recipient and donor CMV serostatus (2). Pre-transplant recipient and/or donor CMV seropositivity is also associated with reduced survival and increased transplant related mortality compared with CMV seronegative pairs(3). Other well established and emerging risk factors for CMV include graft versus host disease (GVHD), corticosteroid use, umbilical cord transplants, haploidentical transplants with post-transplant cyclophosphamide and T-cell depleted grafts (4-6).

However, the increasing complexity and use of T-cell depleting conditioning regimens in HSCT have significantly impacted on the timing and kinetics of CMV viremia in the posttransplant period (1). CMV reactivation is no longer confined to the early post-HSCT period ( $<100$ days) but may occur months later and with multiple recurrences despite adequate treatment(2). In addition, the effective use of universal CMV prophylaxis or pre-emptive therapy in recent years has resulted in a significant decline in CMV tissue invasive end-organ disease from approximately $30 \%$ to $5 \%$ (1). Whereas CMV pneumonitis was once frequently seen, gastrointestinal CMV disease (colitis, ileitis, gastritis) now constitutes greater than $90 \%$ of clinical disease manifestations(1). Finally the development of multi-drug resistant CMV (up to $14.5 \%$ in high risk transplants) and treatment refractory CMV has been found to significantly impact patient morbidity and mortality (7).

\section{Burden of CMV viremia}

The majority of patients with CMV infection will develop CMV viremia without disease, most commonly due to reactivation of latent virus in the patient. There is a 1.8-2.6 times increased risk of death within the first 12 months of HSCT in patients developing CMV viremia compared with no viremia with an impact seen even with relatively low levels of viremia (1). HSCT recipients requiring admission to an intensive care unit (ICU), have a 5.7 times increased risk of death at 12 months if they had CMV reactivation compared with no reactivation (8). The management of CMV viremia is further complicated by potential treatment toxicities (eg. ganciclovir-induced neutropenia, nephrotoxicity) (9), prolonged hospitalisation (10), worse ICU outcomes (8), increased risk for other bacterial or fungal 
infections (11), increased health care costs (10) and contribution to transplant-related mortality (1). Overall, it is estimated that the attributable health care cost of managing CMV is US $\$ 58,000-74,000$ per patient, placing a large economic burden on over stretched health care resources $(10)$.

\section{Laboratory testing of CMV}

Laboratory testing for CMV is performed prior to and after HSCT (see Table 1). Such testing aims to i) establish serostatus of donor/recipient, ii) detect presence of viral copies using nucleic acid testing (NAT) of plasma, whole blood and/or tissue iii) assess antiviral resistance in patients failing antiviral therapy, iv) utilise biomarkers such as CMV-specific T-cell immunity to assess risk of reactivation and $v$ ) for therapeutic drug monitoring (TDM) to assess antiviral levels in blood, particularly in patients failing therapy.

Nucleic acid tests are the most commonly used method to diagnose CMV infection and can be performed on blood (whole blood and plasma), fluids (cerebrospinal and vitreous) and tissue samples (including colonic tissue, bronchoalveolar lavage (BAL) and brain tissue). Both qualitative and quantitative assays are performed using standardized commercial assays with viral loads now reported in standardised form as international units per millilitre $(I U / \mathrm{mL})$ against a World Health Organisation (WHO) standard(12). Laboratories should be enrolled in quality assurance programs with results calibrated to the WHO international standards in order to improve the interpretation of quantitative results from different testing laboratories (12). NAT testing on blood/plasma is generally performed weekly from early post-transplant to approximately day 100 or later post-HSCT in patients with active GVHD on immunosuppression.

Definitive diagnosis of CMV organ disease remains dependent on proven histological evidence of viral tissue invasive effects such as presence of viral inclusion bodies or positive CMV immunohistochemistry staining (13). A blood viral load $>5000 \mathrm{IU} / \mathrm{mL}$ correlates with an increased likelihood of CMV disease in HSCT recipients(14). A crucial observation, however is that CMV disease can occur in a tissue-tropic manner, being present only in some tissue compartments. Substantial differences in viral loads levels in affected tissues and levels in blood have been observed (15). Thus the presence of low or undetectable viral loads in blood does not exclude organ-specific CMV disease, particularly in gastrointestinal and eye disease (15). The detection of CMV DNA in BAL and colonic tissue can occur without end-organ 
disease, and may represent pulmonary viral shedding or DNA contamination from blood. A recent study determined that a CMV BAL DNA cut-off of $500 \mathrm{IU} / \mathrm{mL}$ differentiated between CMV shedding and CMV pneumonia (>500 IU/mL) in HSCT recipients (13).

\section{Immune Monitoring}

Post-transplantation monitoring of CMV immunity in addition to serial quantitation of CMV DNA may better identify patients at risk of CMV complications $(2,16,17)$. New advances in diagnostic assays to rapidly assess CMV-specific immunity include the Quantiferon-CMV® assay (Qiagen), the T-Track ${ }^{\circledR}$ CMV ELISPOT (Lophius Biosciences $\mathrm{GmbH}$ ) and the TSPOT.CMV® assays (Oxford Immunotec, UK) (17). These commercial assays have the advantage of real-time laboratory processing and methods for standardisation.

Studies of CMV immune monitoring in the HSCT population have shown clinical benefits in shortening antiviral treatment duration (16), predicting recurrent CMV reactivation (2) and identifying patients at low risk of CMV complications or with lower CMV viral loads $(2,17)$. Identifying patients that have developed reconstitution of CMV-specific immunity using virological and immunological monitoring post-HSCT significantly reduced the duration of antiCMV pre-emptive treatment by a median of 9 days(16). HSCT recipients with inadequate reconstitution of CMV immunity at day +100 or at the end of first CMV reactivation were much more likely to experience recurrent CMV reactivation (2), implying that the period for CMV monitoring should be extended. Further research is warranted to determine when to perform immune monitoring and how to assess its clinical impact, including the potential to reduce antiviral use or guide prophylaxis duration.

\section{CMV resistance testing}

Testing for CMV resistance may be indicated when recurrence of viremia occurs after initial viral clearance or with failure to achieve $>1 \log 10$ decrease in CMV viral load after $\geq 2$ weeks of full dose antiviral treatment (18). For patients failing antiviral therapy, potential causes include virus mutation leading to antiviral pharmacological resistance or low therapeutic antiviral levels due to underdosing, increased metabolism and/or increased excretion. In the case of oral antivirals, reduced patient compliance or poor absorption particularly if GVHD is present should be considered. Resistance testing typically involves genotyping for UL97 phosphotransferase and UL54 polymerase genes or more recently whole genome sequencing (WGS), although the genotype and phenotype differ in some patients (19). 


\section{Therapeutic drug monitoring}

Therapeutic drug monitoring (TDM) facilitates optimal dosing of antivirals as therapeutic levels may vary depending upon renal function, particularly in the case of ganciclovir (20). Dose adjustment based on population pharmacokinetics Bayesian prediction model has been demonstrated to optimise exposure in SOT(20), although a study of TDM in HSCT showed that immune status is more important than trough ganciclovir levels in predicting clearance of CMV during pre-emptive therapy(21). TDM is not routinely available at present but can be performed in a research setting. Further research is warranted in HSCT recipients to optimise ganciclovir and valganciclovir dosage, and for use with novel antivirals where less is known about dose-response relationships.

\section{Management of CMV viraemia}

Most HSCT programs have adopted a CMV pre-emptive strategy whereby frequent monitoring and the early detection of $\mathrm{CMV}$ virus at a threshold level triggers the commencement of anti-CMV treatment. CMV viremia is usually an indication to start antiviral therapy, however the optimal viral load level at which to commence treatment is unknown; ranging between any detectable viral load to $>1000 \mathrm{IU} / \mathrm{ml}(5)$. The viral load at which preemptive treatment is commenced depends particularly on host immunosuppression, including conditioning regimen, use of $\mathrm{T}$ cell depletion, known pre-transplant CMV serostatus and concomitant immunosuppression for acute GVHD (5). Another important factor is the kinetics of CMV infection, with serial quantitation of viremia to monitor disease progression and treatment responses to assess how much, and how rapidly viremia is progressing (14). Viral load changes $<0.5 \log 10$ are generally considered insignificant (5), although clinical judgement should be used, particularly in highly immunocompromised patients. Monitoring for CMV viremia is recommended for the first 100 days post-HSCT or longer if GVHD is present. However this duration may need extending in patients at risk of late CMV reactivation eg. Tcell depletion or following primary prophylaxis.

Currently valganciclovir and ganciclovir remain the first line antiviral therapy of choice as preemptive or prophylactic therapy(9) (Table 2). The major disadvantages of these agents are myelosuppression (approximately 20-50\% during induction therapy), the requirement for 
intravenous administration for ganciclovir, and development of resistance with long term use $(7,19)$. Although valganciclovir, the oral prodrug of ganciclovir alleviates the requirement for intravenous therapy, dosing requires careful adjustment for renal function, as well as taking into consideration gut absorption, particularly in the presence of GVHD(22). Some institutes use high dose valaciclovir as prophylaxis against CMV in high-risk seropositive umbilical cord transplants (6).

Foscarnet is often used as a second line therapy following ganciclovir failure due to resistance, or adverse effects of ganciclovir, particularly myelotoxicity (5). Inpatient admission is usually required due to the need for intravenous administration, the requirement for electrolyte replacement (particularly management of potassium, calcium and magnesium levels), the pre/post fluid required to prevent nephrotoxicity (occurring in up to $50 \%$ of patients),(23) and the need to monitor closely for adverse effects. Cidofovir is an alternative treatment option, but renal toxicity may limit its use. In a report of 126 HSCT patients treated with cidofovir (with probenecid), the risk of renal toxicity was $26 \%$ (24). Most of the renal toxicity was mild (low-degree proteinuria or mild elevation of the serum creatinine), but some signs of renal impairment remained after drug discontinuation of cidofovir in approximately half of these patients. Cross-resistance occurs between cidofovir and foscarnet with ganciclovir, particularly with mutations in the UL54 gene (19).

\section{Novel anti- CMV Drugs}

Representing a significant advance in the field of CMV management in HSCT are several, novel, clinically effective and well-tolerated anti-CMV agents which may overcome some of the limitations and adverse effects outlined above.

\section{Letermovir}

Letermovir is an anti-CMV specific agent available in both oral and intravenous formulation with excellent in-vitro CMV anti-viral activity (25). The mechanism of action is novel and involves targeting CMV viral terminase and preventing cleavage of DNA in the late stages of viral replication (25). The drug is well tolerated with low rates of myelotoxicity and has been used to successfully treat drug-resistant CMV (26). In a large phase III randomized study of 585 participants comparing letermovir as prophylaxis versus standard of care pre-emptive treatment, there was a significant reduction of $\mathrm{CMV}$ infection seen with letermovir compared to standard of care $(37.5 \%$ vs $60.6 \%)$ at week $24(25)$. In addition, all-cause mortality was 
observed to be lower in the letermovir group at week 24 (10.2\% letermovir versus $15 \%$ standard of care, $\mathrm{p}=0.03)(25)$.

Based on these results, letermovir was recently granted FDA approval for primary CMV prophylaxis in HSCT in the United States. Yet a number of clinical questions remain such as which priority HSCT groups would most benefit from letermovir prophylaxis, what is the efficacy of letermovir in the presence of CMV DNAemia and what is the optimal duration of prophylaxis? It is also unclear what is the threshold to resistance, detected by mutations in UL56 and other genes encoding the terminase complex proteins including pUL89, and pUL51. A case of breakthrough CMV pneumonia occurring whilst on letermovir prophylaxis in a high-risk HSCT recipient was recently reported(27). It is also noted that very high-risk HSCT recipients with early detectable CMV viremia were excluded from the phase III study (25). Cost of the drug to the health care system is also a concern as letermovir should aim to be cost-effective as well as clinically effective.

Letermovir is well tolerated but is only active against CMV. If broad anti-HSV and VZV viral cover is required, then concomitant therapy with anti-herpes agents such as aciclovir or valaciclovir is required. Letermovir also has significant drug interactions that need to be considered especially in relation to ciclosporin, When used concurrently with ciclosporin the dose of letermovir is halved from 480 to $240 \mathrm{mg}$ daily (25). At the time of writing, letermovir is currently only accessible in Australia and many countries under the special access scheme (SAS).

\section{Maribavir}

Maribavir is a novel benzimidazole antiviral agent that is highly potent against CMV, including ganciclovir resistant strains (18). It directly targets the CMV protein kinase UL97 to effectively inhibit viral replication and encapsulation, with mutations in UL97 and UL27 resulting in resistance (18). Further advantages with maribavir are the availability of an oral formulation and the appreciable lack of either myelotoxicity or nephrotoxicity (18). The most commonly reported side effects include metallic taste disturbance and headache (18). In a small case series, maribavir was successful in clearing CMV virus in treatment refractory CMV disease however the development of maribavir resistance in one patient whilst on treatment in a concern (28). 
A large, randomized phase III study of 681 HSCT recipients comparing prophylactic strategies of maribavir to placebo failed to reach the primary end-point of preventing CMV disease at 6 months (4\% maribavir vs 5\% placebo, respectively) (9). Several explanations for these results include the use of low incident primary endpoints such as CMV disease and the dosing regimen chosen for maribavir. Two large phase III studies (2018) evaluating maribavir as a pre-emptive agent compared to valganciclovir and in refractory or drug-resistant CMV compared to standard of care are currently recruiting.

\section{Brincidofovir}

Brincidofovir is the orally available lipid ester prodrug form of cidofovir showing much greater potency against CMV than conventional cidofovir but with much less nephrotoxicity due to its lipid formulation (29). It has activity against HSV, adenovirus and BK virus in addition to CMV (29). A phase III clinical study of HSCT recipients (SUPPRESS) randomized to receive prophylactic brincidofovir or placebo standard of care, failed to reach the primary end point of reduction in CMV infection at week 24 (29). Diarrhoea was a significant adverse event; leading to difficulties in differentiating between gastrointestinal GVHD or brincidofovir-related diarrhoea (29). Higher use of corticosteroids and greater frequency of GVHD were observed in the brincidofovir arm as well as a non-statistically significant increase in mortality (15.5\% brincidofovir vs $10.1 \%$ placebo)(29). Evaluation of brincidofovir to prevent adenovirus infection in paediatric allogeneic HSCT has been terminated and there are no further plans for brincidofovir to be evaluated as an anti-viral for other dsDNA viruses .

\section{Adoptive CMV-specific T cell therapy}

Control of double stranded DNA herpes viruses that establish latency after initial infection is mediated by effective T-cell immunity. Thus, an obvious question has been whether it is possible to reinstate inadequate immunity after allogeneic HSCT using adoptive cellular therapy. This approach has been tested by multiple groups in the last two decades, modelling the positive outcomes demonstrated for EBV specific T-cell therapy in EBV driven posttransplant lymphoproliferative disease. In early phase clinical trials, CMV specific $\mathrm{T}$ cell therapy has proven to be effective in the treatment of active CMV tissue infection. While concerns have been raised about the potential negative effects of T-cell mediated inflammatory responses in critically infected organs such as the lung, eye or brain, adverse clinical outcomes have not been a common finding(30-32). 
Indications for CMV-specific T cells include failure of prolonged or repeated cycles of treatment with ganciclovir and foscarnet or where these drugs cannot be administered due to toxicity. Generation of T cells may be performed using a donor venesection, leukapharesis or directly from the G-CSF primed stem cell donation, where the product is specific for that donor's recipient (33). Another option is to use CMV-specific T cells from third party donors that have been pre-generated and cryopreserved in banks for use at the time of CMV reactivation. In a recent study, $75 \%$ of allogeneic HSCT recipients showed improved viral load responses to CMV (and other viruses including EBV and adenovirus) with partially HLA matched virus-specific $T$ cells (32). Clinical benefits are long-lived despite the fact that persistence of the third party $T$ cells at least in the blood is short term (31). Donor derived CMV-specific T cell therapy in a prophylactic setting showed less frequent use and shortened duration of anti-CMV treatment (30). Use of unmanipulated lymphocytes (DLI) from the original stem cell donor to treat CMV may be of benefit in a minority of cases but is frequently complicated by graft versus host disease and has fallen out of favour in the era of antigen specific T cell therapy.

Within Australia, virus-specific T-cells including CMV-specific $T$ cells may be sourced from at least two academic institutions (Westmead Hospital Cell Therapies Group in Sydney and the Queensland Institute of Medical Research in Brisbane) and are currently being provided on compassionate grounds by Atara Biotherapeutics, a US based biotechnology company. For patients with particularly high risk disease such as those with pre-transplant CMV infection who will be undergoing $T$ cell depleted allogeneic transplantation (typically paediatric patients with immunodeficiency states), there may be sufficient time to plan and generate CMVspecific T cells from the stem cell donor for post-transplant use.

\section{CMV vaccines and monoclonal antibodies}

Immunization against CMV could potentially reduce or prevent CMV disease. Results from a recent phase III HELIOS trial did not demonstrate improvement in overall survival or a reduction in CMV end-organ disease in CMV-seropositive HSCT recipients that received ASP0113, a bivalent DNA vaccine that encodes CMV glycoprotein B and phosphoprotein 65 antigens (34). CSJ148 is a combination of two monoclonal antibodies (LJP538 and LJP539) directed against CMV glycoproteins that has been recently studied in preventing CMV disease in HSCT recipients (35). Final study results are pending. 


\section{Conclusion}

In conclusion, a better understanding of the impact of CMV on transplant outcomes, improvements in viral load and immune monitoring, development of new anti-CMV agents such as letermovir and maribavir together with emerging advances in viral specific $T$ cell adoptive immunotherapy will significantly impact on how clinicians will manage CMV in the future. 
Table 1: Laboratory testing for CMV

\begin{tabular}{|c|c|}
\hline Technique & Summary \\
\hline $\begin{array}{l}\text { Viral load - nucleic acid } \\
\text { test }\end{array}$ & $\begin{array}{l}\text { Detect and quantitate CMV DNA in whole blood or } \\
\text { plasma, sterile fluids and tissue } \\
\text { Provides viral loads (viral copies } / \mathrm{mL} \text { and standardised } \\
\text { as } \mathrm{IU} / \mathrm{mL} \text { ) }\end{array}$ \\
\hline Serology & Indicates past exposure to CMV \\
\hline Immunohistochemistry & $\begin{array}{l}\text { Detection of invasive CMV in tissue specimens using } \\
\text { antibodies to viral proteins for detection of viral } \\
\text { transcription }\end{array}$ \\
\hline Drug resistance & $\begin{array}{l}\text { Genotyping to detect known mutations in UL97, UL54 } \\
\text { and UL56 genes for drug resistance }\end{array}$ \\
\hline $\begin{array}{l}\text { Therapeutic } \\
\text { monitoring }\end{array}$ & Monitoring of ganciclovir and other drug levels \\
\hline CMV immunity & $\begin{array}{l}\text { Quantiferon-CMV or CMV ELISpot assays to assess } \\
\text { CMV T cell immunity, tetramer staining of peripheral } \\
\text { blood to detect T cells directed to specific HLA bound } \\
\text { CMV peptides }\end{array}$ \\
\hline
\end{tabular}


Table 2. Pharmacy

\begin{tabular}{|c|c|c|c|c|c|c|c|c|}
\hline & $\begin{array}{l}\text { Valaciclovir } \\
\text { (2g qid) }\end{array}$ & Ganciclovir & Valganciclovir & Foscarnet & Cidofovir & Brincidofovir & Letermovir & Maribavir \\
\hline Major Toxicities & $\begin{array}{l}\text { Renal } \\
\text { impairment + }\end{array}$ & $\begin{array}{l}\text { marrow } \\
\text { suppression } \\
+++\end{array}$ & $\begin{array}{l}\text { marrow } \\
\text { suppression } \\
+++\end{array}$ & $\begin{array}{l}\text { marrow } \\
\text { suppression + } \\
\text { electrolyte } \\
\text { imbalance +++ } \\
\text { renal } \\
\text { impairment ++ } \\
\text { Gl ++ }\end{array}$ & $\begin{array}{l}\text { marrow } \\
\text { suppression + } \\
\text { renal } \\
\text { impairment +++ }\end{array}$ & $\mathrm{Gl++}$ & none & $\mathrm{GI}+$ \\
\hline Relevant Drug/Drug Interactions & $\begin{array}{l}\text { Antidepressant } \\
\text { S } \\
\text { Verapamil }\end{array}$ & none & none & none & none & none & \begin{tabular}{|l} 
Ciclosporin \\
Tacrolimus \\
Itraconazole \\
Voriconazole \\
Antidepressant \\
s \\
Antiepileptics
\end{tabular} & none \\
\hline $\begin{array}{l}\text { Drug cost per week of prophylaxis } \\
\text { (based on } 75 \mathrm{~kg} \text { patient with normal } \\
\text { renal function) }\end{array}$ & $\$$ & $\$ \$$ & $\$ \$$ & $\$ \$ \$$ & N/A & $\begin{array}{l}\text { unknown - not } \\
\text { available } \\
\text { commercially }\end{array}$ & $\$ \$ \$$ & $\begin{array}{l}\text { unknown - no } \\
\text { available } \\
\text { commercially }\end{array}$ \\
\hline $\begin{array}{l}\text { Drug cost per week of induction } \\
\text { therapy (based on } 75 \mathrm{~kg} \text { patient with } \\
\text { normal renal function) }\end{array}$ & N/A & $\$ \$$ & $\$ \$$ & $\$ \$ \$$ & $\$ \$$ (one dose) & $\begin{array}{l}\text { unknown - not } \\
\text { available } \\
\text { commercially }\end{array}$ & $\mathrm{N} / \mathrm{A}$ & $\begin{array}{l}\text { unknown - no } \\
\text { available } \\
\text { commercially }\end{array}$ \\
\hline
\end{tabular}




\begin{tabular}{|c|c|c|c|c|c|c|c|c|}
\hline Administration Considerations & $\begin{array}{l}\text { Oral, large pill } \\
\text { burden }\end{array}$ & $\begin{array}{l}\text { IV, } \\
\text { can be } \\
\text { administered } \\
\text { via a portable } \\
\text { infusion pump } \\
\text { as outpatient }\end{array}$ & Oral & $\begin{array}{l}\text { IV infusion, } \\
\text { pre/post } \\
\text { hydration, } \\
\text { electrolyte } \\
\text { replacement } \\
\text { essential }\end{array}$ & $\begin{array}{l}\text { IV infusion with } \\
\text { probenecid and } \\
\text { pre/post } \\
\text { hydration } \\
\text { essential }\end{array}$ & Oral & Oral and IV & Oral only \\
\hline Other Considerations & $\begin{array}{l}\text { Use for } \\
\text { prophylaxis } \\
\text { only with } \\
\text { moderate } \\
\text { efficacy }\end{array}$ & $\begin{array}{l}\text { Cytotoxic } \\
\text { manufacturing } \\
\text { facilities } \\
\text { required to } \\
\text { make doses. }\end{array}$ & $\begin{array}{l}\text { Limited data in } \\
\text { serum levels } \\
\text { and doses for } \\
\text { extreme } \\
\text { weights. Lower } \\
\text { absorption in } \\
\text { gut GVHD. } \\
\text { Dose on } \\
\text { Crockroft-Gault } \\
\text { calculated CrCl }\end{array}$ & $\begin{array}{l}\text { Difficult to } \\
\text { administer as } \\
\text { outpatient due } \\
\text { to prehydration } \\
\text { and IV } \\
\text { electrolyte } \\
\text { replacement }\end{array}$ & $\begin{array}{l}\text { SAS, Cytotoxic } \\
\text { manufacturing } \\
\text { facilities } \\
\text { required to } \\
\text { make doses. }\end{array}$ & $\begin{array}{l}\text { No commercial } \\
\text { access. }\end{array}$ & $\begin{array}{l}\text { SAS, } \\
\text { Prophylaxis } \\
\text { only, no data in } \\
\text { pre-emptive/ } \\
\text { treatment }\end{array}$ & $\begin{array}{l}\text { No commercial } \\
\text { access. }\end{array}$ \\
\hline & \multicolumn{8}{|c|}{$\begin{array}{l}\text { Key: } \\
+ \text { Minor, ++ Moderate, +++Major } \\
\$ \text { under } 100 \text { dollars, } \$ 100-1000 \text { dollars, } \$ \$ \$ \text { over } 1000 \text { dollars } \\
\text { GI= gastrointestinal, IV }=\text { intravenous, } \mathrm{CrCl}=\text { creatinine clearance, GVHD = graft versus host disease, SAS = special access scheme } \\
{ }^{*} \text { Although a minor inhibitor, } 1 \mathrm{~A} 2 \text { substrates (many antidepressants, verapamil etc.) should be monitored for toxicity. } \\
{ }^{* *} \text { The major implication of this interaction in } \mathrm{HSCT} \text { is that when ciclosporin is used with letermovir, due to OATP1B1/3 interaction the dose of } \\
\text { letermovir must be halved to } 240 \mathrm{mg} \text { per day. As it is only a minor substrate of } 2 \mathrm{D} 6 / 3 \mathrm{~A} 4 \text {, and with a safe profile, no dose adjustments need to be } \\
\text { made for these. Concomitant drugs that are substrates of } 3 \mathrm{~A} 4 \text { (eg. tacrolimus, ciclosporin, itraconazole etc.), 2C9 or } 2 \mathrm{C} 19 \text { (eg. voriconazole, many } \\
\text { antidepressants, antiepileptics etc.) should be monitored. }\end{array}$} \\
\hline
\end{tabular}

Page 14 of 18

This article is protected by copyright. All rights reserved. 
Table 3: Summary of advances in CMV management in HSCT

\begin{tabular}{|c|c|c|}
\hline & \multicolumn{2}{|l|}{ Key points } \\
\hline Epidemiology & \multicolumn{2}{|c|}{$\begin{array}{l}\text { - } \text { Rates of CMV disease have reduced but CMV viremia is unchanged } \\
\text { - } \\
\text { - } \text { Gastrointestinal CMV disease is now most frequently seen } \\
\text { are observed with changes in HSCT regimens and with GVHD } \\
\text { - } \mathrm{CMV} \text { viremia is associated with higher transplant mortality, ICU outcomes, } \\
\text { increased cost and increased fungal infections }\end{array}$} \\
\hline Diagnostics & $\begin{array}{l}\text { - Change to standardized testing } \\
\text { international units } / \mathrm{mL} \\
\text { - Whole viral genome sequencing avai } \\
\text { - } \mathrm{CMV} \text { immune monitoring to meas } \\
\text { treatment }\end{array}$ & $\begin{array}{l}\text { with CMV viral loads measured in } \\
\text { ability for resistance mutations } \\
\text { ure CMV-specific T-cells may guide }\end{array}$ \\
\hline Drugs & $\begin{array}{l}\text { Prophylaxis } \\
\text { - Letermovir shown to be very } \\
\text { effective for prophylaxis with } \\
\text { reduced overall mortality at } 24 \\
\text { weeks }\end{array}$ & $\begin{array}{l}\text { Treatment } \\
\text { - Maribavir prophylaxis failed to } \\
\text { prevent CMV tissue infection but } \\
\text { is currently under study for } \\
\text { refractory CMV viremia and } \\
\text { resistant CMV }\end{array}$ \\
\hline Immunotherapy & $\begin{array}{l}\text { Prophylaxis } \\
\text { - Donor-derived CMV-T cell } \\
\text { prophylaxis reduces severity of } \\
\text { CMV infection and requirement for } \\
\text { CMV therapy } \\
\text { Prophylactic third party CMV-T cell } \\
\text { therapies are being evaluated }\end{array}$ & $\begin{array}{l}\text { Treatment } \\
\text { - Donor-derived CMV-T cell } \\
\text { treatment is effective treatment } \\
\text { for viremia and tissue infection } \\
\text { - Third party partially HLA matched } \\
\text { CMV T-cells are effective for } \\
\text { recurrent viremia }\end{array}$ \\
\hline
\end{tabular}




\section{References}

1. Green ML, Leisenring W, Xie H, Mast TC, Cui Y, Sandmaier BM, et al. Cytomegalovirus viral load and mortality after haemopoietic stem cell transplantation in the era of pre-emptive therapy: a retrospective cohort study. Lancet Haematol. 2016;3(3):e119-27.

2. Yong MK, Cameron PU, Slavin M, Morrissey CO, Bergin K, Spencer A, et al. Identifying Cytomegalovirus Complications Using the Quantiferon-CMV Assay After Allogeneic Hematopoietic Stem Cell Transplantation. The Journal of infectious diseases. 2017;215(11):1684-94.

3. Schmidt-Hieber M, Labopin M, Beelen D, Volin L, Ehninger G, Finke J, et al. CMV serostatus still has an important prognostic impact in de novo acute leukemia patients after allogeneic stem cell transplantation: a report from the Acute Leukemia Working Party of EBMT. Blood. 2013;122(19):3359-64.

4. Goldsmith SR, Slade M, DiPersio JF, Westervelt P, Lawrence SJ, Uy GL, et al. Cytomegalovirus viremia, disease, and impact on relapse in T-cell replete peripheral blood haploidentical hematopoietic cell transplantation with post-transplant cyclophosphamide. Haematologica. 2016;101(11):e465-e8.

5. Boeckh M, Ljungman P. How we treat cytomegalovirus in hematopoietic cell transplant recipients. Blood. 2009;113(23):5711-9.

6. Hill JA, Pergam SA, Cox E, Xie H, Leisenring WM, Boeckh M, et al. A Modified Intensive Strategy to Prevent Cytomegalovirus Disease in Seropositive Umbilical Cord Blood Transplantation Recipients. Biology of blood and marrow transplantation : journal of the American Society for Blood and Marrow Transplantation. 2018;24(10):2094-100.

7. Shmueli E, Or R, Shapira MY, Resnick IB, Caplan O, Bdolah-Abram T, et al. High rate of cytomegalovirus drug resistance among patients receiving preemptive antiviral treatment after haploidentical stem cell transplantation. The Journal of infectious diseases. 2014;209(4):557-61.

8. Agarwal S, O'Donoghue S, Gowardman J, Kennedy G, Bandeshe H, Boots R. Intensive care unit experience of haemopoietic stem cell transplant patients. Internal medicine journal. 2012;42(7):748-54.

9. Chen K, Cheng MP, Hammond SP, Einsele H, Marty FM. Antiviral prophylaxis for cytomegalovirus infection in allogeneic hematopoietic cell transplantation. Blood advances. 2018;2(16):2159-75.

10. Jain NA, Lu K, Ito S, Muranski P, Hourigan CS, Haggerty J, et al. The clinical and financial burden of pre-emptive management of cytomegalovirus disease after allogeneic stem cell transplantation-implications for preventative treatment approaches. Cytotherapy. 2014;16(7):927-33.

11. Yong MK, Ananda-Rajah M, Cameron PU, Morrissey CO, Spencer A, Ritchie D, et al. Cytomegalovirus Reactivation Is Associated with Increased Risk of Late-Onset Invasive Fungal Disease after Allogeneic Hematopoietic Stem Cell Transplantation: A Multicenter Study in the Current Era of Viral Load Monitoring. Biology of blood and marrow transplantation : journal of the American Society for Blood and Marrow Transplantation. 2017;23(11):1961-7. 
12. Hayden RT, Sun Y, Tang L, Procop GW, Hillyard DR, Pinsky BA, et al. Progress in Quantitative Viral Load Testing: Variability and Impact of the WHO Quantitative International Standards. J Clin Microbiol. 2017;55(2):423-30.

13. Boeckh M, Stevens-Ayers T, Travi G, Huang ML, Cheng GS, Xie H, et al. Cytomegalovirus (CMV) DNA Quantitation in Bronchoalveolar Lavage Fluid From Hematopoietic Stem Cell Transplant Recipients With CMV Pneumonia. The Journal of infectious diseases. 2017;215(10):1514-22.

14. Emery VC, Sabin CA, Cope AV, Gor D, Hassan-Walker AF, Griffiths PD. Application of viral-load kinetics to identify patients who develop cytomegalovirus disease after transplantation. Lancet. 2000;355(9220):2032-6.

15. Yong MK, Ritchie D, Szer J, Cameron PU, Cheng AC, Lewin SR, et al. CMV viral load discordance between plasma and tissue in CMV gastrointestinal disease. 20th International Immunecompromised Host Society Conference; Athens, Greece2018.

16. Navarro D, Amat P, de la Camara R, Lopez J, Vazquez L, Serrano D, et al. Efficacy and Safety of a Preemptive Antiviral Therapy Strategy Based on Combined Virological and Immunological Monitoring for Active Cytomegalovirus Infection in Allogeneic Stem Cell Transplant Recipients. Open Forum Infect Dis. 2016;3(2):ofw107.

17. Yong MK, Lewin SR, Manuel O. Immune Monitoring for CMV in Transplantation. Curr Infect Dis Rep. 2018;20(4):4.

18. Papanicolaou GA, Silveira FP, Langston AA, Pereira MR, Avery RK, Uknis M, et al. Maribavir for Refractory or Resistant Cytomegalovirus Infections in Hematopoietic-cell or Solid-organ Transplant Recipients: A Randomized, Dose-ranging, Double-blind, Phase 2 Study. Clinical infectious diseases : an official publication of the Infectious Diseases Society of America. 2018.

19. Le Page AK, Jager MM, Iwasenko JM, Scott GM, Alain S, Rawlinson WD. Clinical aspects of cytomegalovirus antiviral resistance in solid organ transplant recipients. Clinical infectious diseases : an official publication of the Infectious Diseases Society of America. 2013;56(7):1018-29.

20. Padulles A, Colom H, Bestard O, Melilli E, Sabe N, Rigo R, et al. Contribution of Population Pharmacokinetics to Dose Optimization of Ganciclovir-Valganciclovir in Solid-Organ Transplant Patients. Antimicrob Agents Chemother. 2016;60(4):1992-2002.

21. Gimenez E, Solano C, Azanza JR, Amat P, Navarro D. Monitoring of trough plasma ganciclovir levels and peripheral blood cytomegalovirus (CMV)-specific CD8+ T cells to predict CMV DNAemia clearance in preemptively treated allogeneic stem cell transplant recipients. Antimicrob Agents Chemother. 2014;58(9):5602-5.

22. Winston DJ, Baden LR, Gabriel DA, Emmanouilides C, Shaw LM, Lange WR, et al. Pharmacokinetics of ganciclovir after oral valganciclovir versus intravenous ganciclovir in allogeneic stem cell transplant patients with graft-versus-host disease of the gastrointestinal tract. Biology of blood and marrow transplantation : journal of the American Society for Blood and Marrow Transplantation. 2006;12(6):635-40.

23. Avery RK, Arav-Boger R, Marr KA, Kraus E, Shoham S, Lees L, et al. Outcomes in Transplant Recipients Treated With Foscarnet for Ganciclovir-Resistant or Refractory Cytomegalovirus Infection. Transplantation. 2016;100(10):e74-80. 
24. Ljungman P, Deliliers GL, Platzbecker U, Matthes-Martin S, Bacigalupo A, Einsele H, et al. Cidofovir for cytomegalovirus infection and disease in allogeneic stem cell transplant recipients. The Infectious Diseases Working Party of the European Group for Blood and Marrow Transplantation. Blood. 2001;97(2):388-92.

25. Marty FM, Ljungman P, Chemaly RF, Maertens J, Dadwal SS, Duarte RF, et al. Letermovir Prophylaxis for Cytomegalovirus in Hematopoietic-Cell Transplantation. N Engl J Med. 2017.

26. Kaul DR, Stoelben S, Cober E, Ojo T, Sandusky E, Lischka P, et al. First report of successful treatment of multidrug-resistant cytomegalovirus disease with the novel anti-CMV compound AIC246. American journal of transplantation : official journal of the American Society of Transplantation and the American Society of Transplant Surgeons. 2011;11(5):1079-84.

27. Knoll BM, Seiter K, Phillips A, Soave R. Breakthrough cytomegalovirus pneumonia in hematopoietic stem cell transplant recipient on letermovir prophylaxis. Bone marrow transplantation. 2018.

28. Strasfeld L, Lee I, Tatarowicz W, Villano S, Chou S. Virologic characterization of multidrugresistant cytomegalovirus infection in 2 transplant recipients treated with maribavir. The Journal of infectious diseases. 2010;202(1):104-8.

29. Marty FM, Winston DJ, Chemaly RF, Mullane KM, Shore TB, Papanicolaou GA, et al. A Randomized, Double-Blind, Placebo-Controlled Phase 3 Trial of Oral Brincidofovir for Cytomegalovirus Prophylaxis in Allogeneic Hematopoietic Cell Transplantation. Biology of blood and marrow transplantation : journal of the American Society for Blood and Marrow Transplantation. 2018.

30. Blyth E, Clancy L, Simms R, Ma CK, Burgess J, Deo S, et al. Donor-derived CMV-specific T cells reduce the requirement for CMV-directed pharmacotherapy after allogeneic stem cell transplantation. Blood. 2013;121(18):3745-58.

31. Withers B, Blyth E, Clancy LE, Yong A, Fraser C, Burgess J, et al. Long-term control of recurrent or refractory viral infections after allogeneic HSCT with third-party virus-specific T cells. Blood advances. 2017;1(24):2193-205.

32. Leen AM, Bollard CM, Mendizabal AM, Shpall EJ, Szabolcs P, Antin JH, et al. Multicenter study of banked third-party virus-specific T cells to treat severe viral infections after hematopoietic stem cell transplantation. Blood. 2013;121(26):5113-23.

33. Clancy LE, Blyth E, Simms RM, Micklethwaite KP, Ma CK, Burgess JS, et al. Cytomegalovirus-specific cytotoxic T lymphocytes can be efficiently expanded from granulocyte colony-stimulating factor-mobilized hemopoietic progenitor cell products ex vivo and safely transferred to stem cell transplantation recipients to facilitate immune reconstitution. Biology of blood and marrow transplantation : journal of the American Society for Blood and Marrow Transplantation. 2013;19(5):725-34.

34. Anderholm KM, Bierle CJ, Schleiss MR. Cytomegalovirus Vaccines: Current Status and Future Prospects. Drugs. 2016;76(17):1625-45.

35. Dole K, Segal FP, Feire A, Magnusson B, Rondon JC, Vemula J, et al. A First-in-Human Study To Assess the Safety and Pharmacokinetics of Monoclonal Antibodies against Human Cytomegalovirus in Healthy Volunteers. Antimicrob Agents Chemother. 2016;60(5):2881-7. 


\section{University Library}

\section{- M M N E R VA A gateway to Melbourne's research publications}

Minerva Access is the Institutional Repository of The University of Melbourne

Author/s:

Yong, MK;Gottlieb, D;Lindsay, J;Kok, J;Rawlinson, W;Slavin, M;Ritchie, D;Bajel, A;Grigg, A

Title:

New advances in the management of cytomegalovirus in allogeneic haemopoietic stem cell transplantation

Date:

2020-03-01

Citation:

Yong, M. K., Gottlieb, D., Lindsay, J., Kok, J., Rawlinson, W., Slavin, M., Ritchie, D., Bajel, A. \& Grigg, A. (2020). New advances in the management of cytomegalovirus in allogeneic haemopoietic stem cell transplantation. INTERNAL MEDICINE JOURNAL, 50 (3), pp.277-284. https://doi.org/10.1111/imj. 14462.

Persistent Link:

http://hdl.handle.net/11343/275488 